\title{
General practice: unity in diversity
}

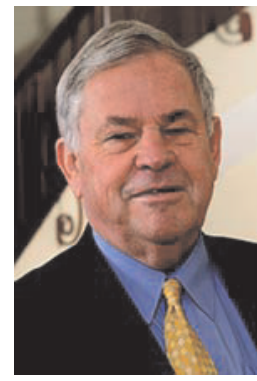

Stephen Leede Editor-in-Chief

mja@mja.com.au

doi: 10.5694/mjal3.c0617

support for mother and child (http://www.nrhm.gov.in/ monitoring/international-advisory-panel/minutes-of-theinternational-advisory-panel.html). There are now 800000 of these women working in India. Simple changes that take account of local needs and conditions can have a huge effect.

Australia has about 25000 general practitioners (http:// www.phcris.org.au/fastfacts/fact.php?id=6775) and I marvel at their commitment and creativity as they have adapted to working together in new ways through Divisions of General Practice and now in the more comprehensive Medicare Locals. They are reformatting the way we provide primary care and adapting to the challenge of long-term support for people with serious and continuing illnesses. But there is more to be done. In this issue (page 581), former Royal Australian College of General Practitioners president Claire Jackson reviews progress in response to the National Primary Health Care Strategy. Despite improvements in integrating primary care with other services, achievements in e-health, an increase in general practice registrar positions, and improved coordination of people with complex needs, we still have some way to go with workforce, access to services, integration with the secondary and aged care sectors, and fiscal efficiency.
The diverse roles of general practitioners, as they care for people in individually negotiated ways, are also featured in this issue. Catling-Paull and colleagues bring some data to the much-contested topic of publicly funded homebirth (page 616). Ward and colleagues (page 590) describe the impact of incentives for general practitioners and parents on rates of vaccination, while Kaczmarek and colleagues (page 624) investigate reasons for increased notifications of pertussis in recent years. Zurzolo and colleagues' finding that many parents of children with food allergies have trouble interpreting food warning labels will not surprise many general practitioners (page 621). Zurynski and Elliott (page 575) highlight the problem of transitional care for older children with rare diseases, and suggest a role for specialist general practice clinics. For clinical fodder, the first article in our new Cardiology series (page 606) revisits the importance of absolute cardiovascular disease risk in primary prevention.

The challenges facing general practice include the sheer diversity of clinical responsibility, making sense of new bureaucratic fantasies and upheavals, adapting to reporting schedules for new services that remind us of the adage "pulling up seedlings to see if the roots are growing", and distribution of an ageing workforce. Matters of money, lagging fee schedules, and work conditions, such as long hours and lack of locum relief, can cause great stress.

Yet general practitioners remain at their posts. Why? I venture it is because they experience great and appropriate satisfaction from the connections they make with the people who come to them for care, as reflected in Links and Bikou's tale of coming to understand a patient at the end of life (page 632). Nothing else makes sense as an explanation.

In this issue, we offer articles drawn from a range of disciplines relevant to general practice. This diversity underscores general practice's central place in the health system of what is, after all, a country blessed with a sophisticated, highly skilled and increasingly integrated health care workforce.

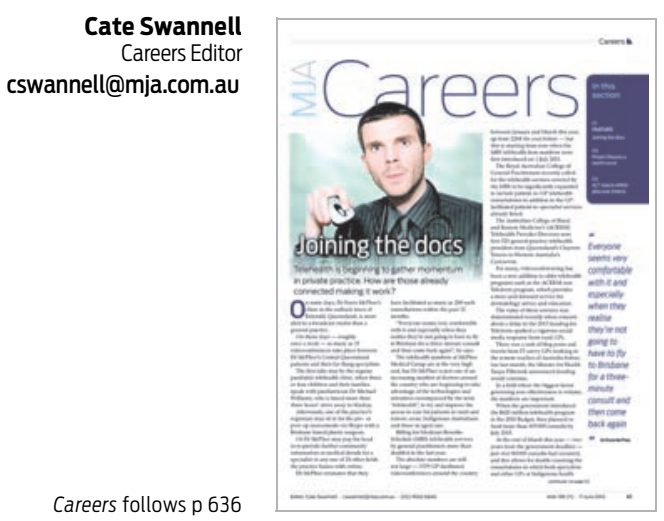

Careers follows $\mathrm{p} 636$

\section{Tel(ehealth)ing it like it is}

Telehealth is beginning to gather momentum in private practice, with the billing for Medicare Benefits Schedule telehealth services by general practitioners more than doubling in the past year. When the government introduced the $\$ 620$ million telehealth program in the 2010 Budget, it planned to fund more than 495000 consultations by July 2015. At the end of March this year - two years from the government deadline - just over
80000 consultations had occurred. Annabel McGilvray talks with connected doctors about their use of the technology in practice, and the future, as government incentives are phased out (page C1). Professor Julian Rait, chair of Anglican Overseas Aid, talks with Cate Swannell about Project Rozana, a three-tiered interfaith plan bringing together Jews, Christians and Muslim Palestinians to improve health care in Gaza (page C4). 